\title{
Kenia: La identificación de las ITR sigue siendo un problema: la prevención es esencial
}

Frontiers in Reproductive Health

Follow this and additional works at: https://knowledgecommons.popcouncil.org/departments_sbsr-rh

Part of the International Public Health Commons, Public Health Education and Promotion Commons, and the Women's Health Commons How does access to this work benefit you? Let us know!

\section{Recommended Citation}

Kenia: La identificación de las ITR sigue siendo un problema: la prevención es esencial, FRONTERAS Resúmenes de Investigación Operativa. Ciudad de México: Population Council, 2000. 


\section{Kenia \\ Infecciones \\ del tracto reproductivo}

Resumen de 107

\section{La identificación de las infecciones del tracto reproductivo sigue siendo un problema: la prevención es esencial}

\begin{abstract}
Más de la mitad de las usuarias de los servicios de planificación familiar y atención prenatal en Nakuru, Kenia, presentaba una o más infecciones del tracto reproductivo (ITR). Aproximadamente una tercera parte de estas infecciones eran de transmisión sexual. Al utilizar algoritmos de manejo sindrómico, que se basan en los síntomas reportados por las mujeres, los proveedores clasificaron correctamente sólo del 5 al 16 por ciento de las mujeres que posteriormente obtuvieron resultados de laboratorio positivos. Dadas las limitaciones del manejo sindrómico, es necesario que los programas insistan en la prevención de infecciones de transmisión sexual (ITS).
\end{abstract}

\section{Antecedentes}

Desde 1990, el Consejo Municipal de Nakuru ha implementado un programa multifacético para reducir la incidencia de infecciones del tracto reproductivo, en particular las de transmisión sexual, incluyendo el VIH/SIDA. El personal de las cinco clínicas del Consejo utiliza lineamientos de manejo sindrómico, los cuales se basan en los síntomas reportados por las usuarias y en los signos clínicos para identificar a las mujeres que tienen una ITR.

En 1998, el Population Council realizó un estudio para evaluar la precisión del manejo sindrómico y para determinar la mejor manera de integrar el tratamiento de las ITR a los servicios de planificación familiar (PF) y de atención prenatal (AP). Entre las fuentes de información se encontraban; (1) los resultados de un examen médico, incluyendo un examen pélvico y la valoración de síntomas y signos clínicos de 906 usuarias de PF y 815 de AP; (2) los factores de riesgo de contagio de las ITS de las usuarias y de sus compañeros; (3) pruebas de laboratorio para cinco ITR, y (4) entrevistas con 18 enfermeras y 195 clientas. Después de una evaluación de los servicios de ITR existentes, 18 enfermeras de las cinco clínicas municipales asistieron a un curso de actualización de tres días sobre el manejo sindrómico, incluyendo capacitación sobre el uso de una lista de verificación para el manejo de usuarias.

\section{Resultados}

Cincuenta por ciento de las clientas de PF y 59 por ciento de las usuarias de AP presentaba por lo menos una ITR, según lo demostraron las pruebas de laboratorio. Una proporción relativamente elevada de usuarias (el 14 por ciento de PF y el 21 por ciento de AP) padecía una o más infecciones de transmisión sexual (chlamydia, gonorrea y tricomoniasis).

Las infecciones vaginales ocasionadas por vaginosis bacterial, tricomoniasis y candidiasis eran más frecuentes (el 47 por ciento de usuarias de $\mathrm{PF}$ y el 56 por ciento de AP) que las infecciones cervicales ocasionadas por gonorrea y/o chlamydia (el 7.5 por ciento de PF y el 9.4 por ciento de AP).

La mayoría de las mujeres a quienes se les detectó una ITR mediante pruebas de laboratorio, eran asintomáticas y no mostraban signos clínicos. Solamente entre el 23 y el 29 por ciento de las usuarias de AP y PF infectadas reportaron uno o más síntomas de ITR, mientras que los proveedores 


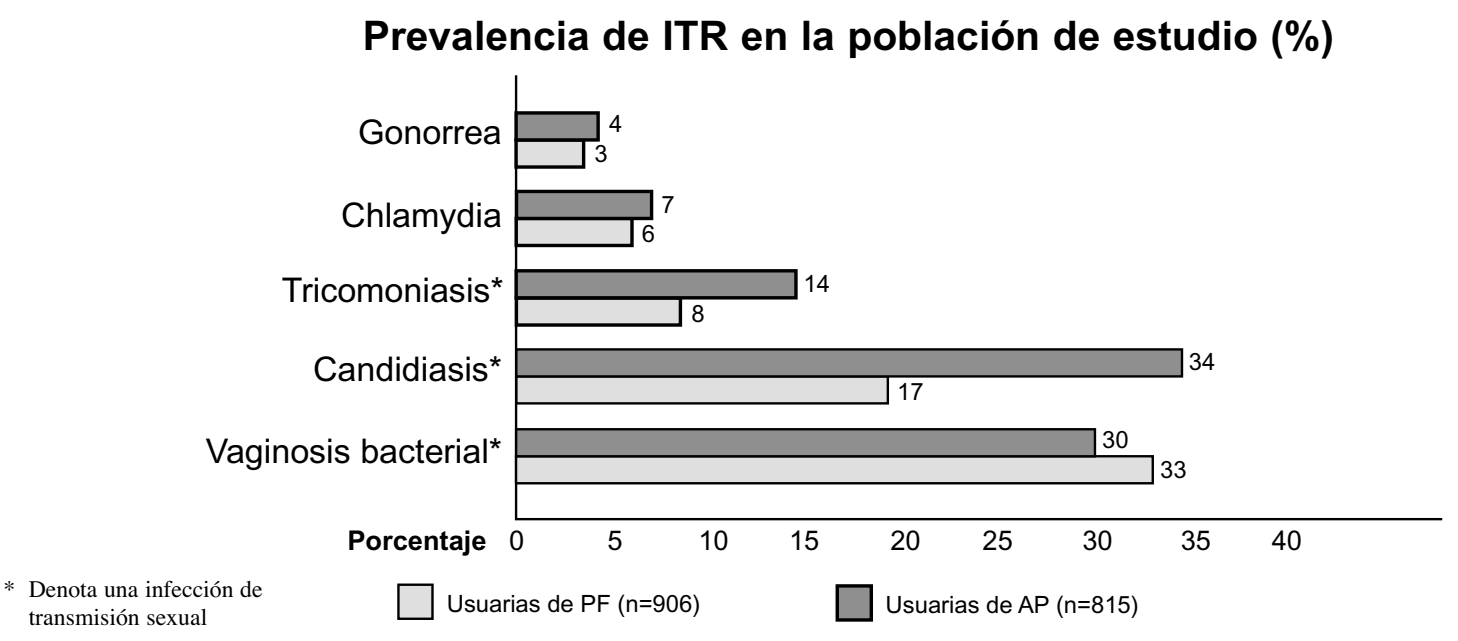

detectaron signos clínicos durante la exploración médica, en un porcentaje de las usuarias infectadas que fluctuó entre el 37 y el 43 por ciento.

Al aplicar los lineamientos del manejo sindrómico, los proveedores pudieron clasificar correctamente como infectadas solamente a una pequeña proporción de las mujeres a las que se había confirmado una ITR mediante pruebas de laboratorio (el 5 por ciento de usuarias de PF y el 16 por ciento de AP).

Los lineamientos actuales para el manejo sindrómico para mujeres clasificadas bajo síndrome de flujo vaginal son más confiables para el manejo de usuarias que padecen una infección vaginal que para las que presentan una infección cervical. La mayoría de las mujeres que los proveedores clasificaron bajo el síndrome de flujo vaginal (el 61 por ciento de usuarias de PF y el 70 por ciento de AP) en realidad presentaban una infección vaginal, mientras que sólo el 11 por ciento de las usuarias de PF y el 8 por ciento de AP que los proveedores habían clasificado bajo dicho síndrome padecía una infección cervical.

La recopilación de información para valorar el riesgo de una ITS de la clienta no mejoró significativamente la capacidad de los proveedores para identificar a las mujeres que padecían infecciones cervicales.

\section{Implicaciones normativas}

Debido al pobre desempeño del manejo sindrómico en mujeres que presentan flujo vaginal como síntoma de una ITS es necesario que los programas hagan énfasis en el tratamiento, mejorando la capacitación de los proveedores en consejería y motivándolos a que eduquen a las usuarias sobre los síntomas de ITS y su prevención, en particular la protección dual.

Si los programas insisten en usar el manejo sindrómico del flujo vaginal, las mujeres clasificadas por los proveedores bajo el síndrome de flujo vaginal deberán recibir primero un tratamiento contra una infección vaginal (i.e. vaginosis bacterial, candidiasis y tricomoniasis) antes que para una infección cervical. De persistir los síntomas, podría ser recomendable dar un tratamiento para infección cervical.

Los algoritmos para el manejo del flujo vaginal necesitan revisarse para que enfaticen el tratamiento de la vaginosis bacterial, que es la ITR más común y que ha sido asociada con un mayor riesgo de infección por VIH así como de la enfermedad pélvica inflamatoria.

Marzo 2000

Solo, Julie; Ndugga Maggwa; James Kariba Wabur; Bedan Kiare Kariuki; and Gregory Maitha. 1999. Improving the Management of STIs among MCH/FP Clients at the Nakuru Municipal Council Health Clinics. Para obtener más información escriba o llame a:

Population Council-Oficina Regional para América Latina y el Caribe. Escondida 110, Villa Coyoacán, 04000, México, D.F. México. Tel. (52) 55-54-03-88; Fax: (52) 55-54-12-26. Correo electrónico: disemina@ popcouncil.org.mx.

Este proyecto fue posible gracias al apoyo de la Agencia de los Estados Unidos para el Desarrollo Internacional (USAID) bajo el contrato número CCP-3030-C-00-3008-00 y los Acuerdos de Cooperación números CCP-3050-A-00-4013-00 y HRN-A-00-98-00012-00. 